\title{
SMOKING LAWS AND THEIR DIFFERENTIAL EFFECTS ON RESTAURANTS, BARS, AND TAVERNS
}

\author{
JOHN DUNHAM and MICHAEL L. MARLOW*
}

\begin{abstract}
This article examines the effect of restrictive smoking laws on restaurants, bars, and taverns. Supporters of these laws often argue that they do not harm firms and may even raise profits. Opponents argue that owners cater to customer smoking preferences, and laws mandating specific policies will negatively impact profits. This article provides a framework for examining the distribution of effects that smoking laws exert on businesses, and demonstrates that changes in total sales or tax revenues do not provide a meaningful understanding of the economic implications because smoking laws exert different effects on different firms. The distribution of these effects is examined using data from a nationwide survey of 1,300 restaurant, bar, and tavern owners. While some subsets of firms are predicted to suffer revenue declines, bars are predicted to be more than twice as likely to experience losses as restaurants. An important implication is that the increasing level of governmental restrictions on smoking in the hospitality sector could gradually impact the types of service available to the public.
\end{abstract}

\section{INTRODUCTION}

Laws restricting smoking in restaurants have been enacted in 32 states. $^{1}$ Supporters argue that these laws do not harm firms and may even raise their profits. Recent studies find that bans on smoking in eating and drinking places have not impacted the profitability of these establishments, suggesting that smoking bans either do not reduce demand or offset sales losses by lowering costs. Opponents of smoking restrictions argue that some owners would find it profitable to allow smoking throughout

*This is a revised version of a paper presented at the Western Economic Association International annual meeting in San Diego, CA, July 2, 1998, and is based in part on a study conducted for Philip Morris Management Corp. We thank William Boyes, Frank Chaloupka, Keith Womer and three anonymous referees for their helpful comments.

Dunham: Manager of Fiscal Issues, Philip Morris Management Corp.

Marlow: Professor, Department of Economics, California Polytechnic State University, San Luis Obispo, CA, Fax 917-663-5379, Email john.dunham@pmmc.com

1. Smoking laws have been imposed on restaurants in Alaska, California, Connecticut, Delaware, Florida, Hawaii, Idaho, Illinois, Iowa, Kansas, Louisiana, Maine, Massachusetts, Michigan, Minnesota, Missouri, Montana, Nebraska, Nevada, New Hampshire, New Jersey, New York, North Dakota, Oklahoma, Oregon, Pennsylvania, Rhode Island, Utah, Vermont, Virginia, Washington, and Wisconsin. their establishments, others to forbid all smoking, and still others to accommodate both smokers and nonsmokers by creating separate areas or investing in partitions, smoking patios or rooms, and air filtration systems.

Little economic research has been published on the effects of smoking laws on the profitability of restaurants, bars, and taverns, and almost none has been directed toward the issue of how these laws may exert differential effects on businesses. This article provides a framework for examining how smoking laws impact establishments based on a number of business attributes. Hypotheses regarding the effect of smoking laws are tested using data from a nationwide survey of 1,300 restaurant and bar owners. The empirical evidence indicates that smoking laws exert differential effects on businesses.

\section{CRITICAL REVIEW OF THE LITERATURE ON SMOKING LAWS}

\section{A. Studies Conclude That Smoking Laws Do Not Harm Firms}

While a full examination of the welfare effects of smoking laws must consider all members of society, our literature review focuses on the economic effects of smoking 
laws on the owners of firms. ${ }^{2}$ Three published studies have concluded that businesses do not suffer reduced sales as a result of bans. Glantz and Smith (1994) compare 15 cities with smoking laws with 15 matched control group cities. They conclude that "legislators and government officials can enact such health and safety requirements to protect patrons and employees in restaurants from the toxins in second-hand tobacco smoke without the fear of adverse economic consequences" (p. 1085). In their study of smoking laws in North Carolina, Goldstein and Sobel (1998) conclude: "Even in the number one tobaccoproducing state in the U.S., ETS regulations present no adverse economic impact, and there is no need for exceptions to the ordinances based on such fears" (p. 286). Sciacca and Ratliff (1998) conclude in their study of Arizona firms that " $t$ ] $]$ his study seems to indicate that prohibiting smoking in all Flagstaff restaurants has had no effect on total restaurant sales.... If these findings are true for communities throughout the United States, then other cities can enact similar laws, which protect patrons and food service workers from tobacco smoke, without concerns that restaurants will lose business" (p. 184).

\section{B. Previous Studies Cannot Uncover Differential Effects}

These three studies all rely on a methodology that examines sales tax revenues in cities that have enacted smoking bans by comparing them with control cities that have not adopted such laws. There are serious methodological problems with this approach. ${ }^{3}$ One problem is that gross retail sales or tax revenues are not useful measures by which to gauge economic effects on a diverse set of firms. For example, on an aggregate basis, firms subject to a ban may show no net effect on sales even though one-half of firms showed gains and the other half exhibited losses. It is not particularly useful to conclude that nothing occurred. Evidence of differential effects was uncovered by a Peat Marwick (1996) study of the 1995 smoking ban in California restaurants.

2. The impact of smoking laws on consumer and producer surplus could also be examined; see Becker and Murphy (1993) and Tremblay and Tremblay (1995).

3. Evan's (1997) review of Glantz and Smith (1997) points out numerous statistical flaws and concludes that findings of no effects are unwarranted.
Their random survey of 600 owners concluded that, while $52 \%$ lost business, $6 \%$ gained business, and the rest did not know. Of the 37 owners with favorable effects, $32 \%$ had outdoor seating, and $57 \%$ had bar seating-areas exempted at that time.

The studies that find no adverse effects are unable to detect differential effects because they aggregate all firms in a community together. This approach conveys confusion about effects exerted on individual firms. But an understanding of differential effects is essential for a comprehensive social welfare analysis and would be necessary in determining appropriate levels of compensation for injured parties within the broader framework of social welfare analysis.

\section{Problems with Control Group Methodology}

Comparisons between cities with smoking laws and those without reveal effects from the laws only when studies properly control for nonban factors that affect sales. Previous studies match cities on the basis of population density and size and median income. However, it is unclear whether these factors control for differences in tourism, weather, tax rates, and employment growth, all of which could also influence businesses. ${ }^{4}$ Moreover, studies compare ratios of restaurant/bar sales to total sales to examine economic effects of laws on firms. Glantz and Smith (1994), for example, state that, "If an ordinance adversely affected restaurants, this fraction would be expected to drop when the ordinance was in force" (p. 1088). However, when nonban factors are not controlled for, this ratio cannot reveal independent effects of laws on firms.

\section{Samples Are Not Random}

Previous studies have not used random samples. For example, Glantz and Smith (1984) chose "the first 15 US cities to enact smoke-free ordinances affecting restaurants" (p. 1087). This sampling poses a problem because these locations have relatively few smokers since otherwise they would probably

4. Glantz and Smith (1994) selected control cities that did not mandate smoking bans; however, Evans (1997) found that more than half were misclassified. 
not be first to legislate bans. A sample selectivity bias arises because such locations would tend to experience relatively little harm from bans. ${ }^{5}$ Moreover, local legislators are likely to be optimistic about local economic conditions since they are unlikely to promote laws that jeopardize tax revenues. The authors then appear to have handpicked locations where economic downturns in the restaurant and bar sectors are unlikely following passage of bans.

Empirical results are then subject to two selection biases. First, authors have "cherrypicked" samples that will exhibit relatively few adverse effects from laws. Second, sampling calls into question conclusions that adoption of similar laws to other locations will yield similar effects. Cities with laws and those without (control groups) are dissimilar when it comes to smoking issues, and it is unlikely that adoption of bans to other cities would go as smoothly as in cities that were first to adopt them.

\section{E. Smoking Bans Are Not Uniformly Enforced}

Smoking bans are not always fully enforced. In California, for example, widespread civil disobedience appears common (Blankstein, 1998; Canto, 1998). This indicates that some percentage of firms would be adversely affected by full compliancethus validating claims that smoking bans adversely affect some firms. Noncomplying firms would also tend to suffer greater effects from fuller compliance. Differences in compliance rates compound the problem of making predictions about how other locations might be impacted.

\section{F. Studies Focus on Revenues, Not Profit}

Owners may attempt to overcome lost business by raising prices or lowering product quality. Owners may also increase advertising or provide promotions that add to costs. If so, profits will change. Previous studies examine only revenues, which do not indicate profits.

5. Dunham and Marlow (2000) argue that, while restaurants that operate in states that have enacted smoking restrictions also tend to offer a larger share of their seating to nonsmoking use, this has little to do with presence of a smoking law. Rather, their customers simply have stronger preferences for such seating.

\section{G. Summary}

Previous studies offer little information about the economic effects of bans on restaurants and bars. Sample selection bias and a statistical methodology based on community averages and control group comparisons do not clearly isolate economic effects. No information on how such effects differ between establishments is reported. Many nonban factors that affect revenues are not properly controlled for, leading to serious questions about whether studies tell us much about the effects of smoking laws on firms. Imperfect enforcement and sample selection problems suggest problems with predictions of how laws would affect other cities. Finally, studies focus on revenues, whereas profits are the more useful indicator of economic effects on firms.

It is also important to realize that findings of no negative effects on revenues in the aggregate could be consistent with a state in which firms have not reached an optimal mix of smoking and nonsmoking seating. However, this situation does not necessarily mean that banning smoking is efficient because changes in community attitudes would most likely lead to seating changes by firms that are more optimal than from government regulation. No adverse revenue effects does not necessarily mean that future revenues would not be lower than they would otherwise have been as firms adapt to changes in smoking preferences. However, lack of adverse effects may simply be a result of serious statistical flaws in previous studies.

\section{AN ECONOMIC MODEL OF SMOKING LAWS}

Coase (1960) provides a general framework for how firms efficiently deal with the smoking issue in the hospitality industry, and demonstrates that private markets internalize externalities when there are trivial transaction costs and property rights are clearly assigned. ${ }^{6}$ Although this study does not focus on the externality issue per se, application of the Coase theorem has important implications about how owners allocate air space within establishments and therefore how smoking laws will affect profits. ${ }^{7}$

6. See Boyes and Marlow (1996) for a more detailed discussion.

7. Ban proponents argue that taxpayers subsidize higher health care costs of smokers. However, Lee 
Although the air space is commonly viewed as a public domain resource, this is untrue within the confines of private firms. Whether an owner caters solely to smokers or to nonsmokers, or accommodates both, depends on customer preferences and marginal costs of accommodation. ${ }^{8}$

Transaction costs are not prohibitive because owners act as intermediaries between smoking and nonsmoking customers. Negotiation occurs via owners who determine what air space allocation is consistent with maximum profits, and in this way, private markets tend toward internalization of externalities. Incorrect decisions displease patrons and lower profits.

Smoking regulations shift ownership of the air space from restaurant and bar proprietors to individuals who prefer that restrictions take place. Options facing customers may change, and smoking customers may choose to spend more time at home rather than going out, while nonsmokers may spend more time at firms when they believe that laws improved environments. ${ }^{9}$

Supply-side effects arise when laws change cost by requiring that firms expend more resources accommodating nonsmokers. In the hospitality industry, profits are determined in a relatively free market, with a large number of suppliers and customers. ${ }^{10}$ Owners determine levels of different attributes, including price, quality, quantity, cuisine, and smoking accommodation to maximize profits. It is an empirical question as to how profits will change following smoking laws. A testable hypothesis is then that restrictions exert differential effects on profits. Effects should also vary between restaurant and bar industries, simply because of differences in

(1991) suggests that bans do not correct this problem, while Allen (1992) argues that society has a right to limit these external costs by imposing bans. See also Gravelle and Zimmerman (1994), who argue that passive smoke risk has been overestimated by OSHA.

8. The importance of accommodating nonsmokers is evident in industry trade magazines. See for example, Walter (1994) and Fruchtman (1992).

9. Corsun et al. (1996) found that smokers dined out less frequently following New York City's ban of 1995 . On average, smokers outspent nonsmokers by $\$ 21.58$ per week.

10. Restaurant and bar markets are not perfectly competitive because products are not homogeneous; however, because of ease of entry, profits might go to normal in the long run. customer bases and marginal costs of accommodation. Another testable hypothesis is that adverse effects are higher for firms catering to relatively many smokers, as firms with few smokers have already found it profitable to voluntarily meet regulations.

\section{DESCRIPTION OF DATA}

Survey data collected by Roper Starch for the National Licensed Beverage Association was used to examine how smoking laws influence firms. The telephone survey was conducted during the period of September 5-12, 1996. The sample consisted of owners/managers of 650 restaurants and 650 bars/taverns across the United States. Samples were drawn in a statistically random manner from national lists provided by Survey Sampling, Inc., and are applicable to all such establishments with a maximum sampling error of approximately \pm 4 percentage points. The survey instrument includes questions pertaining to seating allocations, attitudes toward smoking laws, strategies to deal with smoking/nonsmoking customers, revenues, and projections of effects of smoking laws on revenues. The sample is divided into states with and without smoking laws, using the classification system of the Center for Disease Control that defines smoking laws as laws allowing or requiring nonsmoking sections in restaurants. ${ }^{11}$

This sample provides many advantages over those used in previous studies. This study uses firm-level data, facilitating the analysis of distributional impacts. This is a random sample and does not suffer from selectivity bias problems. The random nature of the selection process also minimizes potential for bias relating to imperfect compliance issues. This sample does not choose firms on the basis of whether they operate under smoking laws, and questions were posed to owners under the assumption of full enforcement. But, as with previous studies, this data set focuses on revenues. An examination of profits would be preferable, but we know of no data that connect profits with smoking laws. However, the

11. Local communities may also impose laws, but these are not included here because we do not know exact locations of firms. However, local laws are less common in states without smoking laws-thus the state measure provides a good measure of restrictions faced by businesses. 
TABLE 1

Expected Revenue Changes

\begin{tabular}{lccc}
\hline & All Firms & $\begin{array}{c}\text { Smoking } \\
\text { Law }\end{array}$ & $\begin{array}{c}\text { No } \\
\text { Law }\end{array}$ \\
\hline $\begin{array}{l}\text { Percentage of Restaurants } \\
\quad \text { Higher }\end{array}$ & $6 \%$ & $6 \%$ & $6 \%$ \\
$\begin{array}{l}\text { Revenues } \\
\text { Lower }\end{array}$ & 39 & 38 & 42 \\
Revenues & & & \\
No Change & 51 & 51 & 49 \\
$\begin{array}{l}\text { Don't Know } \\
\text { Observations }\end{array}$ & 4 & 5 & 3 \\
Percentage of Bars and Taverns & 444 & 206 \\
$\quad$ Higher & $2 \%$ & $2 \%$ & $1 \%$ \\
Revenues & & & \\
Lower & 83 & 85 & 75 \\
$\begin{array}{l}\text { Revenues } \\
\text { No Change }\end{array}$ & 13 & 11 & 18 \\
$\begin{array}{l}\text { Don't Know } \\
\text { Observations }\end{array}$ & 2 & 2 & 6 \\
\hline
\end{tabular}

focus on revenues allows for the direct comparison with results from previous studies. It is also important to note that economists tend to be suspicious of survey data asking about probable effects. We attempt to overcome this problem by comparing responses of owners who have already been subject to smoking restrictions with those who have not, and we are inclined to rely more heavily on responses by firms that already have experienced smoking restrictions.

\section{DISTRIBUTION OF ECONOMIC EFFECTS}

Owners were asked how revenues would change following laws requiring that all firms become virtually nonsmoking. Table 1 displays expected effects on all restaurants, as well as broken down into states with and without smoking laws. From the entire sample, a restrictive smoking law is predicted to raise revenues by $6 \%$ of restaurant owners and lower revenues by $39 \%$. Just over $50 \%$ of owners expected no change, and $4 \%$ provided no prediction.

A $\chi^{2}$ test indicates that the pattern of expected outcomes reported by owners in smoking law states does not differ significantly (5\% level) from those in no-law states. Managers with experience of dealing with laws then offer identical predictions as those without them. This is interesting because ban advocates often argue that owners have no reason to fear economic impacts. But, assurances of no effect appear somewhat misplaced given that $38 \%$ of owners that have already operated under some form of a law predict that virtual bans lower revenues.

Table 1 also displays expected revenue changes by owners of bars. From the entire sample, a ban is predicted to raise revenues by $2 \%$ of owners, lower revenues by $83 \%$, and produce no change by $13 \%$ ( $2 \%$ provided no prediction). Again, using a $\chi^{2}$ test, responses do not differ significantly when broken down into states with and without laws, thus indicating that firms that have already experienced smoking laws offer similar predictions.

A $\chi^{2}$ test also indicates that responses significantly differ between restaurant and bar/tavern owners. Owners of bars and taverns are more than twice as likely to predict decreased revenues, indicating that laws are expected to impose effects that differ across industries.

\section{ARE OWNER RESPONSES CONSISTENT WITH THE ECONOMIC MODEL?}

A potential problem with this analysis stems from the survey nature of the data and that predictions may not reflect actual events - a problem characteristic of survey analysis of possible future events. This shortcoming is ameliorated to large degree by determining how responses vary by current seating allocations. That is, do firms that predict adverse effects tend to allocate relatively few seats to nonsmoking use-or cater to relatively many smokers? If so, those firms catering to relatively few smokers and allocating relatively many seats to nonsmoking use should predict revenue gains or no revenue effects. Moreover, as discussed above, these owners may now attract smokers that previously were not pleased with their policies, and establishments that previously catered to smokers may now compete with other firms on the basis of price or quality.

Only data on restaurants are examined because of little variation in seating allocations of bars and taverns. Table 2 indicates that 40 restaurants predicted revenue gains, 254 predicted revenue losses, and 329 predicted no changes. ${ }^{12}$ Relationships between

12. Twenty seven owners did not know what to predict and have been excluded from this analysis. 
predictions and seating allocations are consistent with expectations. Firms predicting losses have relatively low seating allocations to nonsmoking use (38\%), which strongly indicates that they cater to large populations of smokers. Firms predicting gains report relatively high seating nonsmoking allocations $(70 \%)$, which suggests they expect to attract smokers who previously did not like their nonsmoking policies. Finally, firms predicting no revenue effects have seating allocations (64\%) much higher than those predicting losses, and slightly below those predicting gains.

Table 2 also displays seating allocations broken down into restaurants that operate in states with and without smoking laws. Again, under both conditions, owners predicting revenue gains or no change tended to allocate relatively many seats to nonsmoking use, and owners predicting revenue losses tended to allocate relatively few seats to nonsmoking use.

In sum, predictions of revenue changes are consistent with the economic model of seating allocations and support our empirical evidence demonstrating that laws exert differential effects.

Potential for bias deserves reiteration. Owners may oppose smoking laws for personal reasons and, as a result, exaggerate their expected costs. ${ }^{13}$ One might imagine that smokers are interested in serving other smokers, and they may exaggerate costs of laws. However, we have no information on the likelihood of this event, and know of no data set that contains actual profit effects and seating allocations. Moreover, while owners may have personal views, it remains unclear whether views regarding smoking would override preferences for maximizing the value of their firms. Whether they profit-maximize or cater to personal preferences regarding smoking remains an issue for future research.

\section{LOGIT MODEL OF EXPECTED REVENUE CHANGES}

A qualitative choice model estimates the probability that an owner with a given set of attributes predicts that bans lower revenues. The following logit model is estimated.

$$
\begin{array}{r}
\text { change }_{i}=f\left(\mathrm{NS}_{i}, \operatorname{chain}_{i}, \operatorname{age}_{i},\right. \\
\left.\operatorname{size}_{i}, \operatorname{bar}_{i}, \operatorname{law}_{i}\right)
\end{array}
$$

13. See Berrens et al. (1997) and Kerkvliet (1994) for concerns with survey data. where

$\mathrm{NS}_{i}=$ percentage of seating allocated to nonsmoking use,

chain $_{i}=1$ if firm is a member of a corporate chain and 0 otherwise,

$\operatorname{age}_{i}=$ years firm has been in business,

size $_{i}=$ number of employees (full-time and part-time),

$\operatorname{bar}_{i}=1$ if bar/tavern and 0 otherwise, and

$\operatorname{law}_{i}=1$ if state smoking law is present and 0 otherwise.

The dependent variable change ${ }_{i}=0$ if owner expects either no change or a rise in revenues, and 1 if revenues are predicted to fall.

The percentage of seating that owners allocate to nonsmoking use $\mathrm{NS}_{i}$ is expected to exert a negative influence on the probability that revenues will fall since this variable indicates how many nonsmokers are served. Whether an establishment is a member of a corporate chain is expected to influence responses if chain members offer greater accommodation of smokers and nonsmokers as an element of overall corporate strategy. If true, chain members would be less likely to predict revenue falls and the expected sign on chain $_{i}$ is negative.

Years in business, age $_{i}$, is expected to positively affect probabilities of revenue drops. Accommodation costs may be positively related to age of buildings, and older firms may accommodate less, given that they tend to cater to more established and stable customer bases than newer businesses. Firm size, size $_{i}$, is measured as number of employees and is expected to exert a negative influence when scale economies exist in accommodation. For example, larger firms may find it easier or cheaper to separate smokers from nonsmokers. A positive sign is expected on bar $_{i}$ following the discussion that bars/taverns find it more costly to separate smokers from nonsmokers and their customer bases have less preference for nonsmoking seating. Table 3 displays logit estimations for all firms, restaurants only, and bars/taverns samples.

Estimation based on all firms supports many of the expectations. Higher shares of nonsmoking seating lower the probability that 
TABLE 2

Percentage of Seating Allocations to Nonsmoking Use by Restaurants

\begin{tabular}{lcccr}
\hline Prediction & Mean & Median & Std. Dev. & Number \\
\hline All States & & & & \\
$\quad$ Revenue gains & $70 \%$ & $95 \%$ & 38.9 & 40 \\
$\quad$ Revenue losses & $38 \%$ & $33 \%$ & 36.1 & 329 \\
$\quad$ No changes & $64 \%$ & $75 \%$ & 38.7 & 27 \\
Smoking Law States & & & 39.1 & 167 \\
$\quad$ Revenue gains & $72 \%$ & $45 \%$ & 37.1 & 229 \\
$\quad$ Revenue losses & $41 \%$ & $85 \%$ & 38.3 & 13 \\
$\quad$ No changes & $68 \%$ & & & 87 \\
No-Law States & & $80 \%$ & 39.7 & 100 \\
$\quad$ Revenue gains & $66 \%$ & $25 \%$ & 33.6 & 38.2 \\
$\quad$ Revenue losses & $31 \%$ & $60 \%$ & & \\
$\quad$ No changes & $56 \%$ & & & \\
\hline
\end{tabular}

TABLE 3

Logit Model of Revenue Change

\begin{tabular}{|c|c|c|c|}
\hline & All Firms & Restaurants & Bars/Taverns \\
\hline Constant & $\begin{array}{l}0.26 \\
1.36\end{array}$ & $\begin{array}{l}0.33 \\
1.59\end{array}$ & $\begin{array}{l}1.39^{*} \\
5.35\end{array}$ \\
\hline NS & $\begin{array}{c}-0.02^{*} \\
8.11\end{array}$ & $\begin{array}{c}-0.02 * \\
7.68\end{array}$ & $\begin{array}{l}-0.01^{* * *} \\
1.66\end{array}$ \\
\hline Chain & $\begin{array}{l}-0.29^{* * *} \\
1.86\end{array}$ & $\begin{array}{l}-0.33^{* * *} \\
1.72\end{array}$ & $\begin{array}{r}-0.25 \\
0.84\end{array}$ \\
\hline Age & $\begin{array}{l}0.01^{* *} \\
2.20\end{array}$ & $\begin{array}{l}0.01^{* *} \\
1.95\end{array}$ & $\begin{array}{l}0.01 \\
0.96\end{array}$ \\
\hline Size & $\begin{array}{l}0.01 \\
1.58\end{array}$ & $\begin{array}{l}0.01^{* * *} \\
1.80\end{array}$ & $\begin{array}{c}-.004 \\
0.53\end{array}$ \\
\hline Bar & $\begin{array}{l}1.30^{*} \\
7.69\end{array}$ & & \\
\hline Law & $\begin{array}{l}0.15 \\
0.94\end{array}$ & $\begin{array}{l}0.03 \\
0.17\end{array}$ & $\begin{array}{l}0.43 \\
1.62\end{array}$ \\
\hline Log Likelihood & -648.73 & -380.88 & -265.52 \\
\hline Obs with Dep $=0$ & 465 & 369 & 96 \\
\hline Obs with Dep $=1$ & 793 & 254 & 539 \\
\hline Observations & 1258 & 623 & 635 \\
\hline
\end{tabular}

Dependent variable $=0$ if owner expects no change, or a revenue increase, $=1$ if owner expects a revenue decrease. Asymptotic $t$ statistics are given below estimated coefficients.

${ }^{*},{ }^{* *},{ }^{* *}$ denote significant at $.01, .05$, and .10 levels, respectively.

owners expect adverse revenue effects, chain members are less likely to expect revenue reductions, older firms are more likely to expect revenue declines, and bar owners are more likely to expect revenues to fall than are restaurant owners. ${ }^{14}$ Firm size and pres-

14. Alternative specifications checked for model stability between small and large establishments, young and old establishments, and chain versus independent firms. In all cases, the percentage of nonsmoking seating remained significant and of the same sign. The smoking law variable remained insignificant. The other variables retained the same properties. ence of state smoking laws do not significantly influence the equation.

Estimation based on only restaurants supports the same significant relationships, except of course the bar $_{i}$ variable has been removed from the equation. In addition, firm size is estimated to exert a weak (.10 level) positive effect on the probability that an owner expects a revenue loss.

Estimation based on only bars/taverns yields just one significant factor: the share of nonsmoking seating exerts a negative effect, 
as expected, and is consistent with the other estimations. This effect is only weakly significant at the .10 level, but estimation results suggest that most bar/tavern owners expect that a virtual smoking ban will lower revenues.

\section{CONCLUSION}

This article examines the revenue effects that smoking laws exert on restaurants, bars, and taverns as predicted by 1,300 owners of these firms. While a subset of firms is likely to suffer adverse revenue effects following a smoking ban, bars and taverns are predicted to experience adverse effects more than twice as often as restaurants. This is consistent with "reality checks" that indicated that revenue predictions reflect owner perceptions of customer preferences regarding smoking. Adverse revenue effects were most often predicted by owners allocating relatively little seating to nonsmoking use, and positive or neutral effects were most often predicted by owners who allocated relatively much of their seating to nonsmoking use.

The interesting public policy issue concerns the distribution of effects, and not the average effect exerted on a particular industry. It is true that $51 \%$ of restaurant owners predicted no revenue changes, but it is inappropriate to conclude that no effect would be exerted on this industry since $39 \%$ of owners predicted that revenues would fall following a virtual smoking ban. Similarly, not all bars and taverns are predicted to experience identical effects, but the distribution of predicted effects is much tighter ( $83 \%$ predict revenues to fall) for this industry.

\section{REFERENCES}

Allen, Jeremiah M., "Environmental Economics and the Social Cost of Smoking: A Comment," Contemporary Policy Issues, 10:1, January 1992, 101.

Becker, Gary S., and Kevin M. Murphy, "A Simple Theory of Advertising as a Good or Bad," Quarterly Journal of Economics, 108:4, November 1993, 941964.

Berrens, Robert P., Alok K. Bohara, and Joe Kerkvliet, "A Randomized Response Approach to Dichotomous Choice Contingent Valuation," American Journal of Agricultural Economics, 79:1, February 1997, 252-266.

Blankstein, Andrew, "Enforcement Clouds Issue of Smoking Ban," Los Angeles Times, Metro Sec. September 21, 1998, p. 3.
Boyes, William J., and Michael L. Marlow, "The Public Demand for Smoking Bans,” Public Choice, 88:1-2, July 1996, 57-67.

Canto, Minerva, "Californians Puff on Despite Ban," Washington Post, Sec. A, September 24, 1998, p. 7.

Coase, Ronald H., "The Problem of Social Cost," Journal of Law and Economics, 3, October 1960, 1-44.

Corsun, David L., Cheri A. Young, and Cathy A. Enz, "Should NYC's Restaurateurs Lighten Up?" Cornell Hotel and Restaurant Administration Quarterly, 37:2, April 1996, 25-33.

Dunham, John, and Michael L. Marlow, "The Effects of Smoking Laws on Seating Allocations of Restaurants, Bars, and Taverns," Economic Inquiry, 38:1, January 2000, 151-157.

Evans, Michael K., "A Review of "The Effect of Ordinances Requiring Smoke-Free Restaurants on Restaurant Sales,"” www.speakup.org/pdf/ misc003.pdf, March 1997.

Fruchtman, David J., "Smoking in RestaurantsClearing the Air," Heating/Piping, Air Conditioning, 64:7, July 1992, 65.

Glantz, Stanton A., and Lisa R. A. Smith, "The Effect of Ordinances Requiring Smoke-Free Restaurants on Restaurant Sales," American Journal of Public Health, 84:7, July 1994, 1081-1085.

, "The Effect of Ordinances Requiring SmokeFree Restaurants and Bars on Revenues: A FollowUp," American Journal of Public Health, 87:10, October 1997, 1687-1693.

Goldstein, Adam O., and Rachel A. Sobel, "Environmental Tobacco Smoke Regulations Have Not Hurt Restaurant Sales in North Carolina," North Carolina Medical Journal, 59:5, Sept./Oct. 1998, 284-288.

Gravelle, Jane G., and Dennis Zimmerman, "Cigarette Taxes to Fund Health Care Reform: An Economic Analysis," CRS Report for Congress, March 8, 1994.

Kerkvliet, Joe, "Estimating a Logit Model with Randomized Data: The Case of Cocaine Use," Australian Journal of Statistics, 36:1, April 1994, 9-16.

Lee, Dwight, R., "Environmental Economics and the Social Cost of Smoking," Contemporary Policy Issues, 9:1, January 1991, 83-92.

Peat Marwick LLP, for the Southern California Business Association, "The Impact of the Current and Proposed Smoking Bans on Restaurants and Bars in California," April 1996.

Sciacca, John, and Michael I. Ratliff, "Prohibiting Smoking in Restaurants: Effects on Restaurant Sales," American Journal of Health Promotion, 12:3, Sept./Oct. 1998, 176-184.

Tremblay, Carol H., and Victor J. Tremblay, "The Impact of Cigarette Advertising on Consumer Surplus, Profit and Social Welfare," Contemporary Economic Policy, 13:1, January 1995, 113-124.

Walter, Kate, "Design: No-Smoking Sections," Restaurant Business, 93:1, January 1, 1994, 114. 